\title{
Variable Density Multilayer Insulation for Cryogenic Storage
}

\author{
A. Hedayat \\ Space Transportation Directorate \\ Sverdrup Technology, Inc., MSFC Group \\ Huntsville, AL 35806 \\ T. M. Brown, L. J. Hastings, J. Martin \\ Space Transportation Directorate \\ Marshall Space Flight Center \\ Huntsville, AL 35812
}

\begin{abstract}
Two analytical models for a foam/Variable Density Multi-Layer Insulation (VD-MLI) system performance are discussed. Both models are one-dimensional and contain three heat transfer mechanisms, namely conduction through the spacer material, radiation between the shields, and conduction through the gas. One model is based on the methodology developed by McIntosh ${ }^{1}$ while the other model is based on the Lockheed semi-empirical approach ${ }^{2}$. All models input variables are based on the Multi-purpose Hydrogen Test Bed (MHTB) geometry and available values for material properties and empirical solid conduction coefficient. Heat flux predictions are in good agreement with the MHTB data. The heat flux predictions are presented for the foam/MLI combinations with $30,45,60$, and $75 \mathrm{MLI}$ layers
\end{abstract}

\section{INTRODUCTION}

Future space programs and missions require efficient delivery of large payloads over great distances. The Cryogenic Fluid Management (CFM) plays a vital role in the development of high-energy upper stage vehicles. Therefore, efficient and reliable insulation materials are a curcial part of future space exploration. The importance of insulation in cryogenics is easily realized by noting that the heat of vaporization of cryogenic liquids, as well as, their specific heats are small, and it takes small amount of heat flux to boil off the cryogenic liquids or to raise the system temperature

Multi-layer insulations are typically high-vacuum systems made of many radiation shields between the hot and cold boundaries. They normally consist of an assembly of numerous thin plastic films coated on one or both sides by a thin-deposited layer of high reflectance metal, usually aluminum or gold. The multilayer insulation systems can be used in both high-temperature and cryogenic applications, however; the insulation material, the arrangement, and heat transfer characteristics are quite different. A detailed review of MLI is provided by Tein and Cunnington ${ }^{3}$. 
MLI systems are made up of multiple Double Aluminized Mylar (DAM) (or similar materials) radiation shields, supported by a suitable spacer material (often dacron mesh netting). While radiation is generally the dominant heat transfer, solid conduction through the spacer material becomes an issue at low temperatures such as those experienced by the inner MLI layers isulating a cryogenic fluid tank. To optimized MLI systems for this type of application, colder inner layers are separated by greater distance than the warm outer layers where radiation dominates the heat transfer. This type of MLI is referred as Variable Density because the layer spacing varies across the MLI system. The spacing in a VD-MLI system is controlled by the addition of bumper strips of different thickness. Bumper strips are constructed by folding the dacron netting. Thus, thickness is easily varied by varying the number of folds in the bumper strips

MLI systems are suitable for low pressure environments where radiation is the dominant heat transfer mechanism while at higher pressure simple foam insulation easily outperform MLI. Thus, many space vehicle insulation systems are hybrids, combining foam insulation for atmospheric heat transfer protection and MLI for optimum resistance during orbital/space flight A unique multilayer insulation concept for orbital cryogenic storage was experimentally evaluated provided by Hastings and Martin ${ }^{4}$ in 1996 using a large scale test article ( 3 meter diameter by 3 meter long with a volume of 18 cubic meters) termed the Multipurpose Hydrogen Test Bed (MHTB). A foam substrate was used to protect against ground hold/ascent flight environments, and successfully allowed the use of a dry nitrogen purge as opposed to a helium purge subsystem normally required with MLI in cryogenic applications. The MLI (45 layers of DAM with dacron net spacers) was designed for an on-orbit storage period of 45 days and included several unique features including: a variable layer density (reduces weight and radiation losses), larger but fewer DAM perforations for venting during ascent to orbit (reduces radiation losses). Additionally, the roll wrap installation process provided a robust MLI and reduced both assembly man-hours and seam heat leak. A detailed description of the MHTB and its VDMLI was provided by Hastings and Martin.

The orbit hold test periods produced heat leaks of 0.085 and $0.22 \mathrm{Watts} / \mathrm{m}^{2}$ with warm boundary temperatures of $164 \mathrm{~K}$ and $305 \mathrm{~K}$, respectively. When compared to the best previously measured performance with a traditional MLI system a $41 \%$ heat leak reduction was achieved with 25 fewer layers. Additionally, when compared with calculated performance of a constant-density MLI (with standard perforations) using the industry standard "Lockheed equation" ${ }^{2}$ and holding the blanket weight constant, the variable-density MLI heat leak was "half" that with the standard blanket at the highest boundary temperature. Similarly, standard blankets of equal performance weighed $18 \mathrm{~kg}$ (40 lbs) more (or 74 percent more) than the variable density MLI. System performances do, however, tend to converge at the lowest boundary temperature of $160 \mathrm{~K}$ due to the decreased significance of radiation exchange between layers.

The foam/MLI system performed exceptionally well in the orbit hold testing when compared with historical data and predictions based on constant density MLI concepts. 
Therefore, the focus in this paper is on analytical modeling of the MLI performance during orbital coast periods

\section{MODELING OVERVIEW}

Simulations of two models of VD-MLI performance are compared. The Layer-by-Layer model is based on a methodology developed by McIntosh, and the other model is a modification of the Lockheed method. The analytical modeling of the insulation during orbital coast periods is discussed in subsequent sections.

\section{Layer-by-Layer Model}

The Layer-by-Layer model is based on McIntosh's work on a separated mode equation to simulate MLI performance and accounts for three modes of heat transfer: thermal radiation between shields, gas conduction, and solid conduction through the separator materials. The total heat flux through the MLI is given by

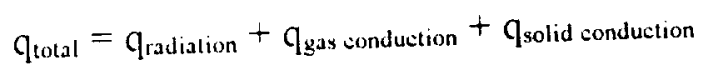

The radiation heat transfer is,

$$
\mathrm{q}_{\text {radiation }}=\sigma\left(\mathrm{T}_{\mathrm{w}}{ }^{4}-\mathrm{T}_{\mathrm{C}}{ }^{4}\right) /\left(1 / \varepsilon_{\mathrm{w}}+1 / \varepsilon_{\mathrm{c}}-1\right)
$$

where

$\sigma=$ Stephan-Boltzmann constant $=5.675 \mathrm{E}-8 \mathrm{~W} / \mathrm{m}^{2}-\mathrm{K}^{4}$

$\mathrm{T}_{\mathrm{w}}=$ temperature of warm surface, $\mathrm{K}$

$T_{C}=$ temperature of the cold surface, $K$

$\varepsilon_{\mathrm{w}}$ and $\varepsilon_{\mathrm{c}}$ are the emissivities of the warm and cold surfaces, respectively.

The gas conduction equation is provided by McIntosh who adopted an earlier formulation by Corruccini ${ }^{6}$.

$$
\mathrm{q}_{\text {gas conduction }}=\mathrm{C}_{\mathrm{l}} \mathrm{P} \alpha\left(\mathrm{T}_{\mathrm{w}}-\mathrm{T}_{\mathrm{C}}\right)
$$

where

$\mathrm{k}_{\mathrm{g}}=\mathrm{C}_{1} \mathrm{P} \alpha$

$\mathrm{k}_{\mathrm{g}}=$ gas conduction, $\mathrm{W} / \mathrm{m}^{2}-\mathrm{K}$

$\mathbf{P}=$ gas pressure, $\mathrm{pa}$

$C_{1}=[(\gamma+1) /(\gamma-1)][R / 8 \pi M T]^{1 / 2}$

$\alpha=$ accommodation coefficient

$\gamma=\mathrm{C}_{\mathrm{p}} / \mathrm{C}_{\mathrm{v}}$

$\mathrm{R}=$ gas constant, $8.314 \mathrm{~kJ} / \mathrm{mol}-\mathrm{K}$

$\mathrm{M}=$ molecular weight of gas, $\mathrm{kg} / \mathrm{mol}$

$\mathrm{T}=$ temperature of vacuum gage, normally $300 \mathrm{~K}$

For air, $C_{1}=1.1666$ and for helium 2.0998 .

Conduction through the solid is expressed as, 


$$
\mathrm{q}_{\mathrm{solid} \text { conduction }}=\mathrm{K}_{\mathrm{s}}\left(\mathrm{T}_{\mathrm{H}}-\mathrm{T}_{\mathrm{C}}\right)
$$

where,

$\mathrm{K}_{\mathrm{s}}=\mathrm{C}_{2} \mathrm{f} \mathrm{k/DX}$

$\mathrm{C}_{2}=$ an empirical constant

$\mathrm{f}=$ relative density of the separator compared to solid material

$\mathrm{k}=$ separator material conductivity, $\mathrm{W} / \mathrm{m}-\mathrm{K}$

$\mathrm{DX}=$ actual thickness separator between reflectors, $\mathrm{m}$

Curve fit equations have been applied to express thermal conductivity for dacron, silk net, and glass paper as a function of temperature, T. For dacron, the following equation is provided:

$$
\begin{gathered}
\mathrm{k}=0.017+7 \mathrm{E}-6^{*}(800-\mathrm{T})+0.0228 \ln (\mathrm{T}) \\
\mathrm{C}_{2}=0.008
\end{gathered}
$$

\section{Modified Lockheed Model}

The Lockheed model also allows three heat transfer mechanisms, namely: conduction through solid, conduction through gas, and radiation between shields. A semi-empirical expression is developed and used to approximate the variation of conductance with temperature in terms of conductivity, modulus of elasticity, and Poisson's ratio of spacer material. The solid conductive heat transfer with a nonlinear dependency of thermal conductivity of the spacer fibers is described as

$$
\mathrm{q}_{\text {solid conduction }}=A\left(N^{*}\right)^{n} T_{m}\left(T_{H}-T_{C}\right) / N
$$

where $A$ is an empirical coefficient, $N^{*}$ represents layer density, $T_{m}$, represents the average temperature of hot and cold boundaries $\left(T_{m}=\left(T_{H}+T_{C}\right) / 2\right), T_{H}$ is the temperature of hot boundary, and $T_{C}$ is the temperature of the cold boundary. $\mathrm{N}$ represents the number of radiative shields. The gas conductive heat transfer under free-molecule conditions, is shown as

$$
q_{\text {gas conduction }}=\beta(\gamma+1 / \gamma-1) /\left(R / 8 \pi M \mathrm{~T}_{m}\right) 0.5 \mathrm{P}\left(\mathrm{T}_{\mathrm{H}}-\mathrm{T}_{\mathrm{C}}\right)
$$

where $\mathrm{P}$ is pressure in torr, $\mathrm{T}$ is temperature in degree $\mathrm{K}, \mathrm{M}$ is molecular weight, $\gamma$ is the specific heat ratio, and $\beta$ is an empirical parameter. The radiative heat transfer between the perforated shields is given by

$$
\mathrm{q}_{\text {radiation }}=\mathrm{B} \varepsilon \sigma\left(\mathrm{T}_{\mathrm{H}}{ }^{4.67}-\mathrm{T}_{\mathrm{C}}^{4.67}\right) /\left(\mathrm{N}_{\mathrm{s}}+1\right)
$$

$\varepsilon$ is emissivity of the shields and B is an empirical parameter. The total heat transfer can then be expressed as

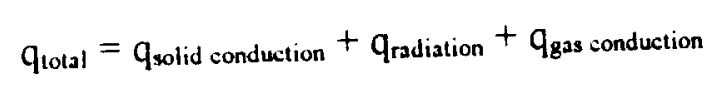




$$
\begin{aligned}
q_{\text {total }}=A\left(N^{*}\right)^{n} T_{m}\left(T_{H}-T_{C}\right) /\left(N_{s}+1\right)+B \sigma\left(T_{H}{ }^{4.67}-T_{C}{ }^{4.67}\right) /\left(N_{s}+1\right) \\
+C P(x, T)\left(T_{H}{ }^{(m+1)}-T_{C}^{(m+1)} /\left(N_{s}+1\right)\right.
\end{aligned}
$$

where $P(x, T)$ is the pressure within the insulation as a function of position and local temperature, and coefficients $\mathrm{A}, \mathrm{B}$, and $\mathrm{C}$ as well as the exponents $\mathrm{m}$ and $\mathrm{n}$ are derived from the particular insulation system and intestial gas.

For perforated aluminized shields, nitrogen gas, and glasstissue spacer material, the suggested Lockheed equation for the total heat transfer becomes the following:

$$
\begin{aligned}
q_{\text {lotal }}=7.30 \times 10^{-8}\left(\mathrm{~N}^{*}\right)^{2.63} \mathrm{~T}_{\mathrm{m}}\left(\mathrm{T}_{\mathrm{H}}-\mathrm{T}_{\mathrm{C}}\right) / \mathrm{N}_{\mathrm{s}} & +7.07 \times 10^{-10} \varepsilon\left(\mathrm{T}_{\mathrm{H}}{ }^{4.67}-\mathrm{T}_{\mathrm{C}}{ }^{4.67}\right) / \mathrm{N}_{\mathrm{s}} \\
& +1.46 \times 10^{4} \mathrm{P}\left(\mathrm{T}_{\mathrm{H}}{ }^{0.52}-\mathrm{T}_{\mathrm{C}}{ }^{0.52}\right) / \mathrm{N}_{\mathrm{s}}
\end{aligned}
$$

where

$$
\begin{aligned}
& \mathrm{P}=\text { pressure in torr } \\
& T=\text { temperature in degree } K \\
& N^{*}=\text { layers } / \mathrm{cm}
\end{aligned}
$$

$$
\begin{aligned}
& q_{\text {total }}=\text { total heat transfer in } \mathrm{w} / \mathrm{m}^{2} \\
& \varepsilon=0.043 \\
& N_{\mathrm{s}}=\text { number of shields }
\end{aligned}
$$

In the original Lockheed equation, the spacer material and the shield hole sizes were different than those of the test article, therefore, the parameters $A$ and $B$ were adjusted for the MHTB insulation. The coefficient $B$ in the Lockheed equation accounts for the radiation between the shields and was provided for perforated shields of $0.119 \mathrm{~cm}(0.047$ inches) hole diameter and a fractional open area of 0.01 . To adjust the value of $B$ for the perforated shields used in the MHTB MLI [hole diameter of $1.27 \mathrm{~cm}(0.5$ inches) and fractional open area of 0.02 ], reference 7 was used. The adjusted value of $B$ is calculated to be $4.944 \mathrm{E}-10$. On the other hand, the coefficient $\mathrm{A}$ influences the conduction through the spacer. The spacer material in the original Lockheed equation was tissuglass, while in the test article, dacron spacer material was used. To modify the solid conduction term, the dacron conductivity function provided by McIntosh is incorporated into the conduction term. Therefore, the Modified Lockheed equation becomes the following:

$$
\begin{aligned}
\mathrm{Q}_{\text {total }}= & 2.4 \times 10^{-4 *}(0.017+7 \mathrm{E}-6(800-\mathrm{T})+0.0228 \ln (\mathrm{T}))^{*}\left(\mathrm{~N}^{*}\right)^{2.63}\left(\mathrm{~T}_{\mathrm{H}}-\mathrm{T}_{\mathrm{C}}\right) / \mathrm{N}_{\mathrm{s}}+ \\
& 4.944 \times 10^{-10} \varepsilon\left(\mathrm{T}_{\mathrm{H}}^{+.67}-\mathrm{T}_{\mathrm{C}}^{4.67}\right) / \mathrm{N}_{\mathrm{s}}+1.46 \times 10^{4} \mathrm{P}\left(\mathrm{T}_{\mathrm{H}}^{0.52}-\mathrm{T}_{\mathrm{C}}^{0.52}\right) / \mathrm{N}_{\mathrm{s}}
\end{aligned}
$$

\section{RESULTS AND DISCUSSIONS}

Figure 1 represents a schematic of the cryogenic tank with a foam/MLI combination with five different segments. The first segment is the foam. The second, third and fourth segments represent the three segments of MLI with different layer density and number of shields. The layer density $N^{*}$, and number of shields for MLI segments 1 thru 3 are 8, 12 , and 16 layers $/ \mathrm{cm}$, and $10,15,20$ shields respectively. Finally, the last segment is considered to be the shroud with an emissivity of 0.04 . For the steady state conditions, the heat flux through the MLI system is modeled using the modified Lockheed equation. The 
model was comprised of described five different segments. Therefore, the heat transfer model consisted of conduction through the foam, 3 segments of MLI using the Lockheed equation for each segment, and radiation exchange between the shroud and the last MLI shield. The Cold Temperature Boundary condition at the interior of the foam and hot temperature, respectively. Experimental data contained a Cold Temperature of $20 \mathrm{~K}$ while the Hot Boundary Temperatures are $164 \mathrm{~K}, 235 \mathrm{~K}$, and $305 \mathrm{~K}$. At steady state conditions, the following relations can be written as

$$
\mathrm{Q}_{\text {foam }}=\mathrm{Q}_{\text {layer } 1}=\mathrm{Q}_{\text {layer2 }}=\mathrm{Q}_{\text {layer3 }}=\mathrm{Q}_{\text {shroud }}
$$

The Q's, $T_{1}, T_{2}$, and $T_{3}$ are unknowns. Using equations (13), a system of four equations with four unknowns can be developed. Because of the radiation terms, this system of equations is nonlinear and is solved iteratively. First, for prescribed cold and hot boundary temperatures, initial MLI segment interface temperatures are assigned. Then, heat rate through each segment is calculated. Using the heat rate and guessed temperature, the resistant of each segment is computed. Then, new temperatures are computed using the new heat rate and resistance of each segment. The process is repeated until the solution converges. The convergence of the solutions implies that the total heat transfer rate through each segment is the same and the temperature of each MLI segment interface for two consecutive iteration steps becomes equal within an allowable difference.

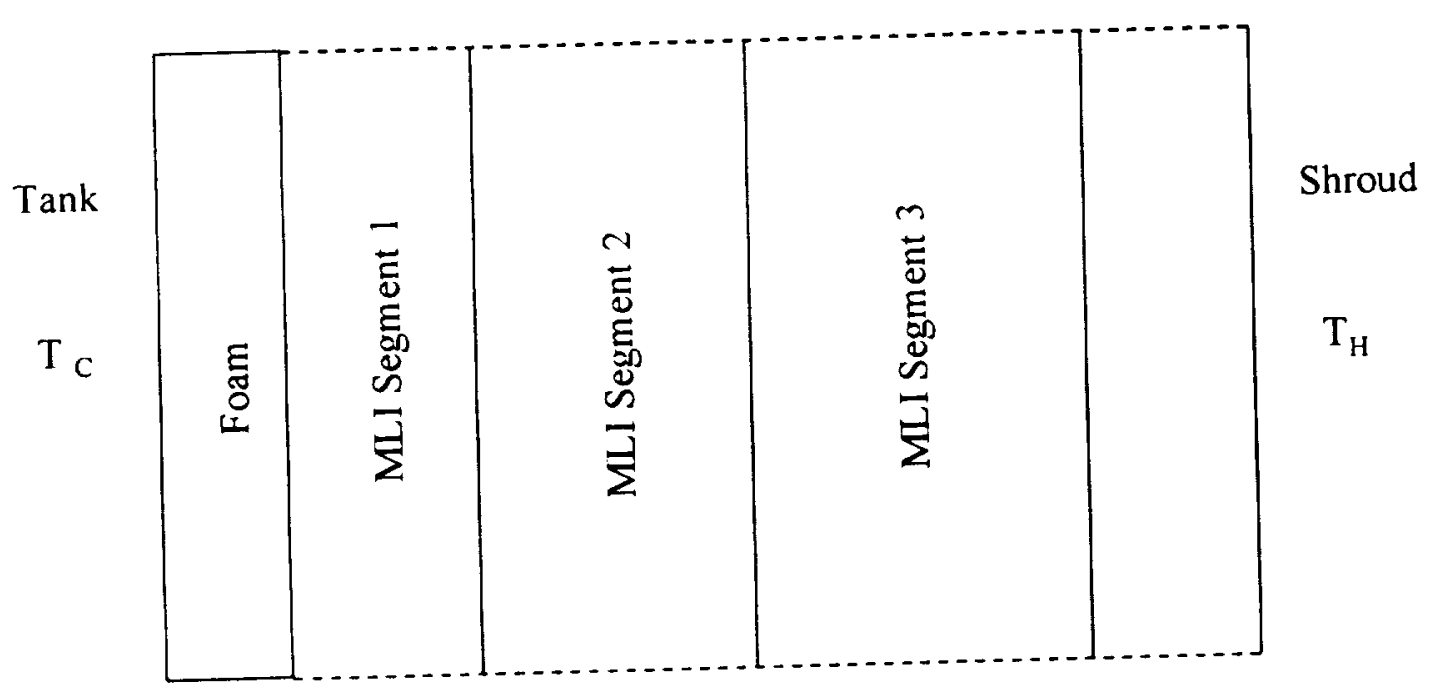

Figure 1. Schematic of Foam/MLI System

In the Layer by Layer approach, the foam, each shield layer, and the shroud are considered to be separate nodes. Therefore, the foam/MLI system model is comprised of 47 nodes For the steady state, heat flux through the MLI system was calculated using McIntosh 
model and applying similar computational procedure as that of Lockheed model as described earlier. Based on the described methods, two spreadsheet models were developed. These spreadsheets could be useful tools in design optimization and performance evaluation of MLI systems.

Comparison between the heat flux values predicted by both models and those of the measured data is shown in Figure 2. Compared with the MHTB test data, for higher value of Hot Boundary Temperature, the heat flux values predicted by Layer-by-layer model and modified Lockheed equation are within $5 \%$ and $8 \%$, respectively. While for the lower values of Hot Boundary Temperature, the predictions are within $34 \%$ and $30 \%$ for the Layer-by-Layer and Modified Lockheed, respectively.

Comparison Between two models are extended in three hypothetical foam/MLI systems with the different shield layer densities than that of the test article. The MLI systems simulated are 30,60, and 75 layers. Each of these foam/MLI system is considered to have similar physical and thermal properties as those of 45 layer foam/MLI system. Figures 3, 4 , and 5 illustarte the predicted heat flux for the MLI systems of 30,60 , and 75 layers, respectively. The predicted heat flux values at the highest Hot Boundary Temperature are within $6 \%$. As the Hot Boundary Temperature is lowered, heat fluxes predicted by both models converge to similar values. The results for the foam/MLI system indicate that both the Layer-by-Layer and Modified Lockheed models simulations are consistently within $6 \%$.

In conclusion, either spreadsheet model can be utilized to predict the performance of either the MHTB type foam/MLI combination or the MLI alone. In the development of the analytical model for the MLI, it was observed that the larger, more widely spaced ventilation holes provided a significant radiation blockage advantage as compared with the standard, closely space holes. The variable density contributed to a weight reduction or performance increase due to reduced conduction with fewer layers to perform the same task. The lack of seams, butt joints and structural support pins no doubt contributed to the performance improvement as well. The foam insulation not only enabled the elimination of a helium purge system, but also reduced the ground hold heat leak sufficiently to improve the effective density of the loaded hydrogen as compared with a "MLI" only concept. 


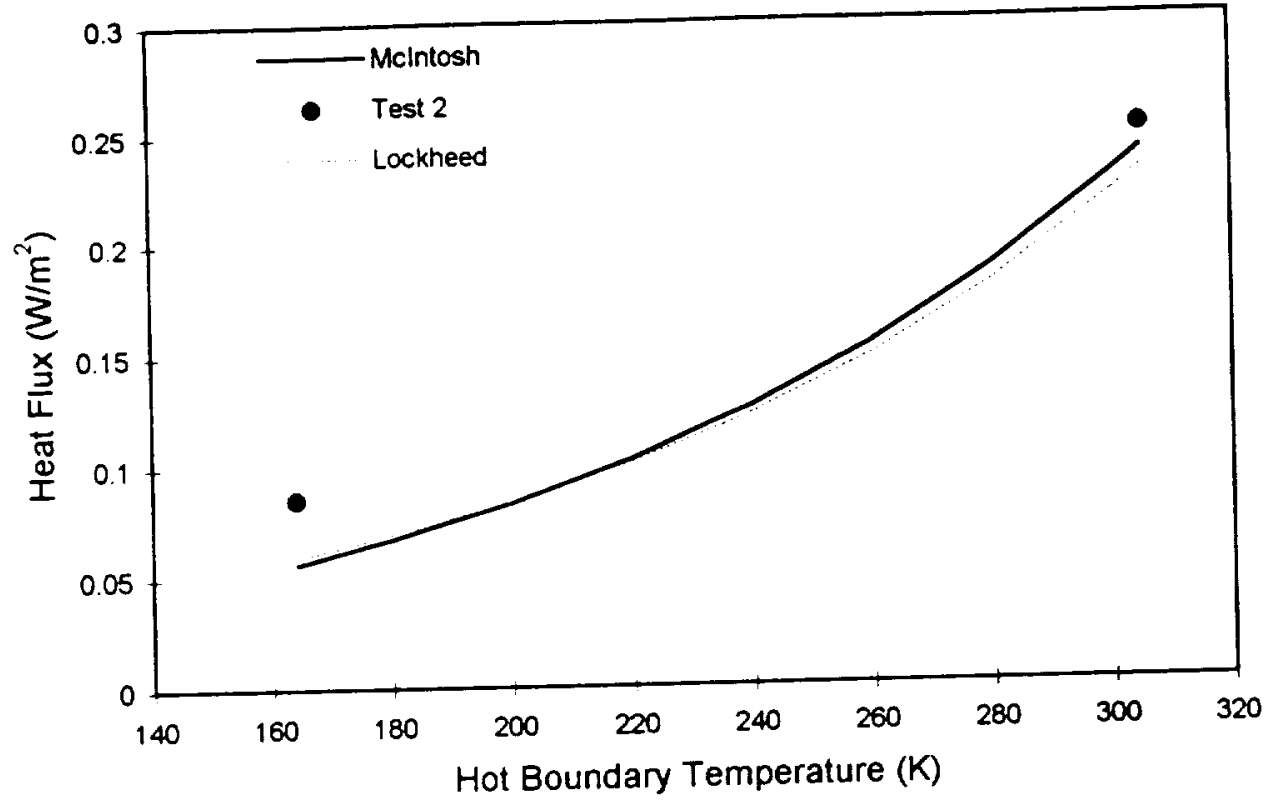

Figure 2. Heat Flux Predictions for 45 Layers MLI

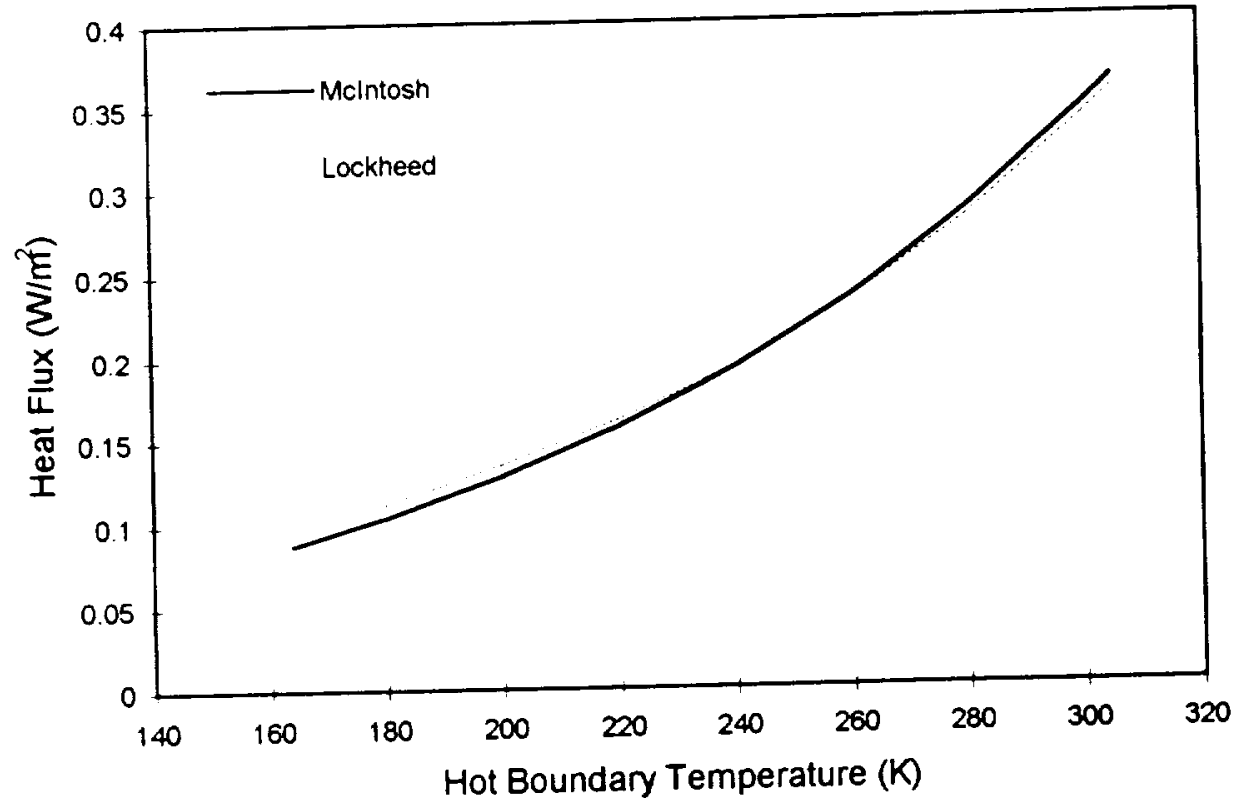

Figure 3. Heat Flux Predictions for 30 Layers MLI 


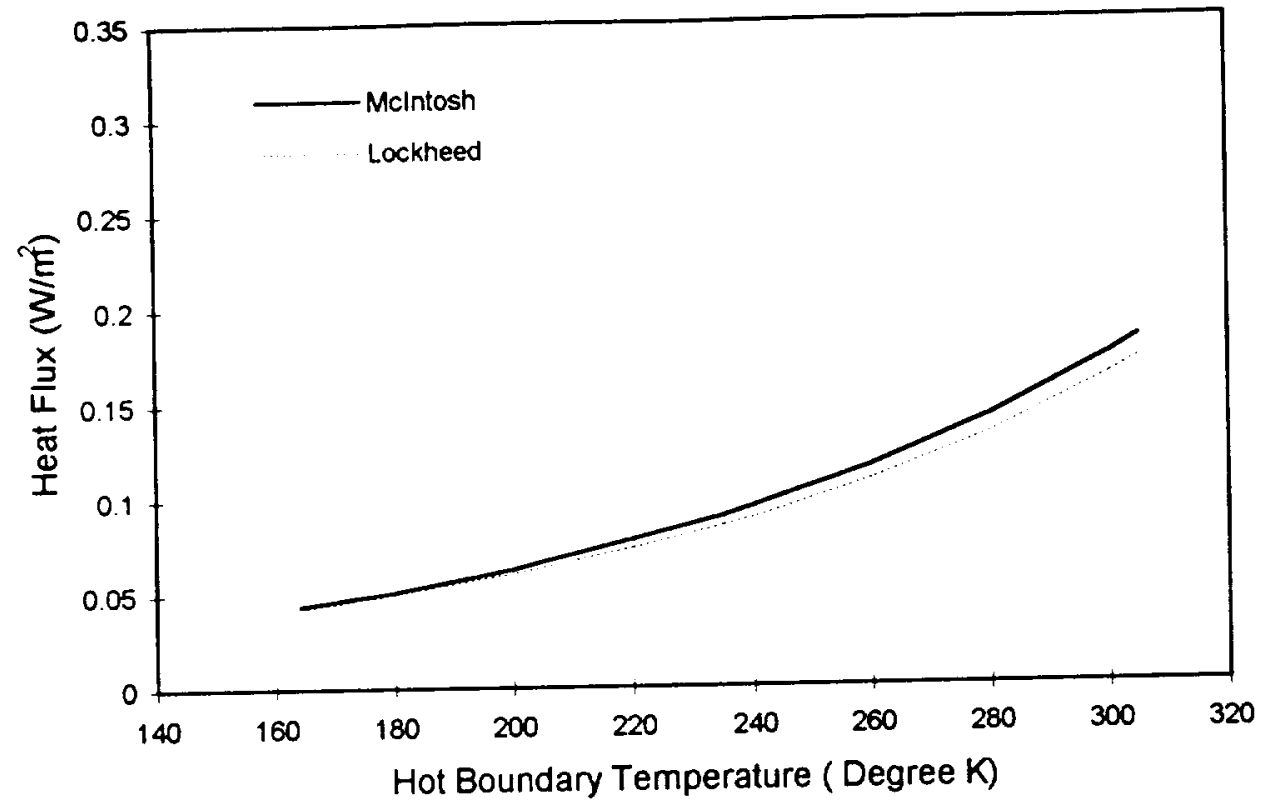

Figure 4. Heat Flux Predictions for 60 Layers MLI

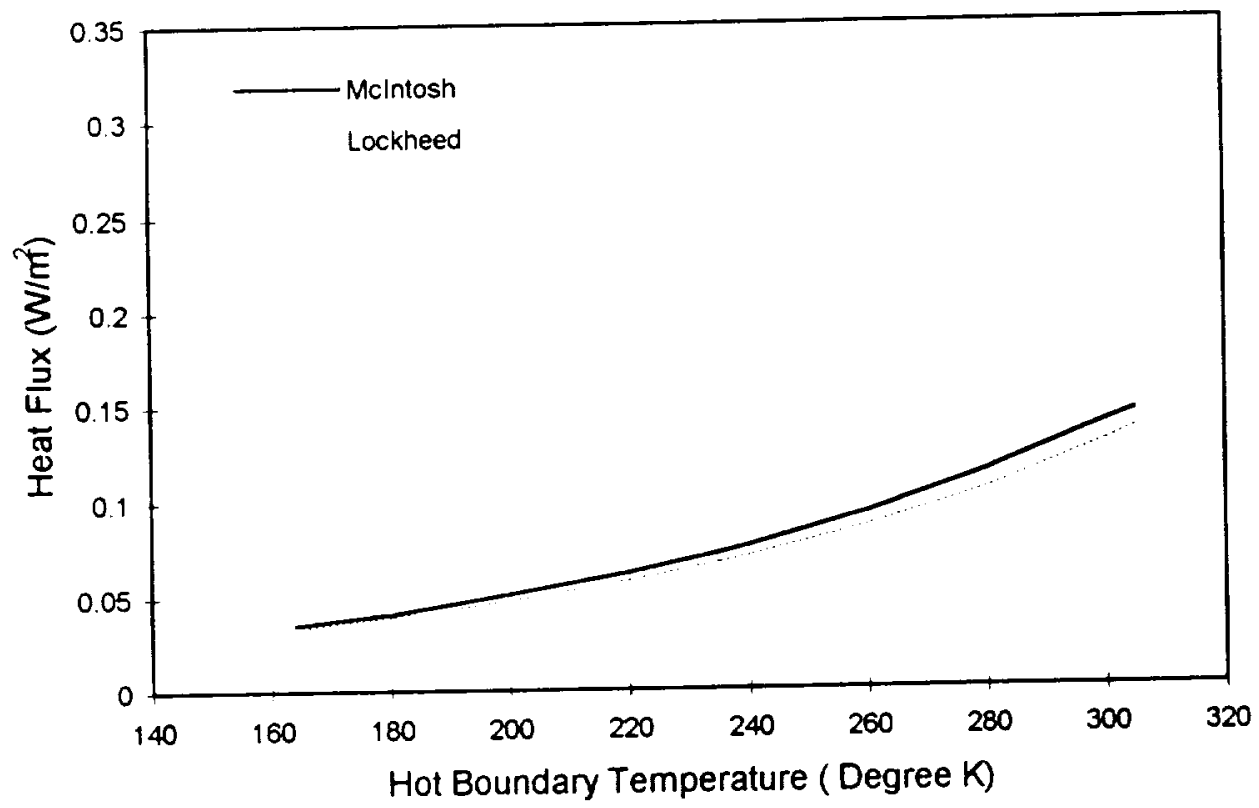

Figure 5. Heat Flux Predictions for 75 Layers MLI 


\section{ACRONYMS AND ABBREVIATIONS}

$\begin{array}{ll}\mathrm{cm} & \text { centimeter } \\ \mathrm{hr} & \text { Hour } \\ \mathrm{Kn} & \text { Knudsen number } \\ \mathrm{K} & \text { Degree Kelvin } \\ \mathrm{m} & \text { Meter } \\ \mathrm{MHTB} & \text { Multi-Purpose Hydrogen Test Bed } \\ \text { MLI } & \text { Multi-Layer Insulation } \\ \text { VD-MLI } & \text { Variable Density Multi-Layer Insulation } \\ \mathrm{W} & \text { Watts }\end{array}$

\section{REFERENCES}

1. McIntosh, G. E., "Layer by layer MLI calculation Using a Separated Mode Equation," Cryogenic technical Services Inc., Bolder, CO.

2. Keller, C. W., Cunnington, G. R., and Glassford, A. P.:"Thermal Performance of Multi-Layer Insulations, Final Report, Contract NAS3-14377, Lockheed Missiles \& Space Company, 1974.

3. Tein, C. L., and Cunnigton, G. R., "Cryogenic Insulation Heat Transfer," Advances in Heat Transfer, pp. 349-417, Volume 9, 1973.

4. Hastings, L. J. and Martin, J. J., "Experimental Testing of a Foam/Multilayer Insulation (FMLI) Thermal Control System (TCS) for use on a Cryogenic Upper stage," Space Technology \& Applications International Forum, $1^{\text {st }}$ Conference on Orbital Vehicles, Albuquerque, NM, Jan. 25-28, 1998.

5. Fredrickson, G. O., "Investigation of High-Performance Insulation Application Problems, Final Report". Contract NAS8-21400, McDonnell Douglas Astronautics Co Report MDC G4722, August 1973.

6. Corruccini, R. J., "Gaseous Heat Conduction at Low Pressures and temperatures," Vacuum, VII\&VIII, pp. 19-29, 1959

7. "Thermal Insulation Systems," Chapter 4, NASA Report N67-38580, August 1967. 